\title{
Residential Radon Exposure and Cigarette Smoking in Association with Lung Cancer: a Matched Case- control Study in Korea
}

\section{Eung Joo Park}

Yonsei University Wonju College of Medicine

\section{Hokyou Lee}

Yonsei University College of Medicine

Hyeon Chang Kim

Yonsei University College of Medicine

\section{Seung soo Sheen}

Ajou University Hospital

\section{Sang Baek Koh}

Yonsei University Wonju College of Medicine

Ki Soo Park

Gyeongsang National University Graduate School of Medicine

\section{Nam Han Cho}

Ajou University School of Medicine and Graduate School of Medicine

Cheol-Min Lee

Seokyeong University

Dae Ryong Kang ( $\nabla$ dr.kang@yonsei.ac.kr)

https://orcid.org/0000-0002-8792-9730

\section{Research article}

Keywords: radon, cigarette smoking, lung cancer

Posted Date: October 4th, 2019

DOl: https://doi.org/10.21203/rs.2.15523/v1

License: (c) (1) This work is licensed under a Creative Commons Attribution 4.0 International License.

Read Full License

Version of Record: A version of this preprint was published at International Journal of Environmental Research and Public Health on April 24th, 2020. See the published version at 
https://doi.org/10.3390/ijerph17082946. 


\section{Abstract}

Background: Residential radon exposure and cigarette smoking are the two most important risk factors for lung cancer. The combined effects thereof were evaluated in a multi-center matched case-control study in South Korea.

Methods: A total of 1,038 participants were included, comprising 519 non-small cell lung cancer cases and 519 age- and sex- matched community-based controls. Residential radon levels were measured for all participants. Multivariate logistic regression was used to calculate odds ratios (OR) for lung cancer according to radon exposure (high $\geq 100 \mathrm{~Bq} / \mathrm{m}^{3}$ vs. low $<100 \mathrm{~Bq} / \mathrm{m}^{3}$ ), smoking status, and combinations of the two after adjusting for age, sex, indoor hours, and other housing information.

Results: The median age of the participants was 64 years, and $51.3 \%$ were women. The adjusted ORs (95\% confidence intervals [Cls]) for high radon and cigarette smoking were 1.56 (1.03-2.37) and 2.53 (1.60-3.99), respectively. When stratified according to combinations of radon exposure and smoking status, the adjusted ORs ( $95 \% \mathrm{Cls}$ ) for lung cancer in high-radon non-smokers, low-radon smokers, and high-radon smokers were 1.40 (0.81-2.43), 2.42 (1.49-3.92), and 4.27 (2.14-8.52), respectively, with reference to low-radon non-smokers.

Conclusion: Both residential radon and cigarette smoking were associated with increased odds for lung cancer, and the difference in ORs according to radon exposure was much greater in smokers than in nonsmokers.

\section{Background}

An aggressive cancer, lung cancer is the most common cause of cancer death worldwide [1]. While prognoses of lung cancer at advanced stages remain disappointing [3], survival rates for early localized disease are often promising [2], although early detection of lung cancer is uncommon. Therefore, current preventive strategies focus on controlling environmental hazards or routine radiologic screening of individuals at high risk for lung cancer [4].

The two most important environmental contributors to lung cancer development are cigarette smoking and radon exposure. Of these, exposure to radon indoors has garnered greater interest as a risk factor for lung cancer, as radon is a colorless and odorless gas that is ubiquitous in rocks and soils and, thus, can accumulate in buildings [5]. The association between radon exposure and lung cancer has been widely reported [6-8], and the combined effect of radon and tobacco smoke is thought to be higher than additive $[9,10]$. However, studies on the combined effect of radon and smoking on lung cancer have primarily focused on exposure to radon at high concentration sites, such as uranium mines [11-13]. Accordingly, we aimed to assess the interaction between residential radon exposure and cigarette smoking in association with lung cancer in a matched case-control study in Korea.

\section{Methods}




\section{Study design and participants}

The Korea-Integrated Radon Exposure Epidemiology Statistics (K-iREES) study enrolled a total of 6,582 individuals between October 2015 and March 2018 from seven tertiary hospitals and four communitybased cohorts. The hospital-based participants were recruited from Severance Hospital, Seoul; Asan Hospital, Seoul; St. Mary's Hospital, Seoul; Ajou University Hospital, Suwon; Wonju Severance Hospital, Wonju; Gyeongsang University Hospital, Changwon; and Pusan University Hospital, Yangsan. The community-based participants were recruited from the Cardiovascular and Metabolic Diseases Etiology Research Center (CMERC), Seoul [14]; the Ansung-Ansan Korean Genome and Epidemiology Study (KoGES) [15]; the Namgaram cohort [16], Gyeongnam; and the Wonju-Pyeongchang KoGES [15]. The study regions were selected to include various regional radon exposure levels according to data obtained from the National Institute of Environmental Research (2011-2016). The selected study regions and their corresponding exposure levels are depicted in Figure 2, with correction for seasonal variations.

From the study hospitals, patients aged 19 to 80 years who had been diagnosed with non-small cell lung cancer (NSCLC) stage I to Illa were included. The controls were selected from community-based cohort participants aged 19 to 80 years who had no known diagnosis of lung cancer. All participants had lived in their homes for 2 years or longer. A total of 1,343 individuals, including 526 hospital-based and 817 community-based participants, had radon measurements taken in their homes. For each hospital-based lung cancer patient, a community-based control was matched for sex and age ( $<65$ or $\geq 65$ years), and 1:1 sampled using SAS proc surveyselect. Finally, 519 cases and 519 matched controls were analyzed. The study protocol was approved by the Institutional Review Board of Yonsei University College of Medicine (CR315030).

\section{Measurement of residential radon levels}

Residential radon levels were measured at two locations in each study home where individuals tend to spend most of their time: the living room and the bedroom. Alpha-track detectors (Raduet Model RSV-8; Radosys Ltd., Budapest, Hungary) were used as a passive radon measuring device. The measuring devices were positioned away from household electrical appliances, windows, or sealed drawers. The measurements were made over 3 months, and the average of measurements at both locations in the house was taken. Given that indoor radon levels are highest in the winter and lowest in the summer, seasonal corrections were made with average temperature, wind speed, and other factors taken into consideration [17]. The residential radon levels were dichotomized into high $\left(\geq 100 \mathrm{~Bq} / \mathrm{m}^{3}\right)$ or low $(<100$ $\mathrm{Bq} / \mathrm{m}^{3}$ ) according to World Health Organization reference data [18].

\section{Smoking history and covariables}


The K-iREES study was designed to investigate factors associated with radon exposures and related health problems. Questionnaires were used to identify demographics, health-related behaviors, such as cigarette smoking, and the characteristics of individual homes, including indoor cracks, ventilation, housing types, construction year, etc. Cigarette smoking was defined as having smoked five or more packs in a lifetime. Second-hand smoking was defined as living together with or working in proximity to a current smoker.

\section{Statistical analysis}

Participant characteristics are reported as a mean \pm standard deviation, median [interquartile range], or frequency (percent). Intergroup comparisons were conducted using T-tests for continuous variables and x2-tests for categorical variables. We used multivariate conditional logistic regression to calculate odds ratios (OR) and $95 \%$ confidence intervals (Cl) for lung cancer according to residential radon exposure (high vs. low), smoking status, and combinations of the two (low-radon dwelling non-smokers [reference], high-radon dwelling smokers, low-radon dwelling smokers, and high-radon dwelling smokers), after adjusting for second-hand smoking, sleeping hours, indoor hours, housing type, floor, presence of cracks, and green ratio. All analyses were performed using SAS version 9.4 (SAS Institute Inc., Cary, NC, USA). Map-visualization of radon levels was computed using R version 3.4.3 (R Foundation for Statistical Computing, Vienna, Austria).

\section{Results}

\section{Participant characteristics}

Descriptive statistics of the 519 hospital-based lung cancer cases and the 519 age- and sex-matched community-based controls are reported in Table 1. In both the case and control groups, the median age was 64 years, and $51.3 \%$ were women. Mean residential radon levels were $65.46 \mathrm{~Bq} / \mathrm{m}^{3}$ and $73.75 \mathrm{~Bq} / \mathrm{m}^{3}$ $(P=0.013)$ in the case and control groups, respectively. Among the cases and controls, the proportions of individuals exposed to high levels of residential radon $\left(\geq 100 \mathrm{~Bq} / \mathrm{m}^{3}\right)$ were $13.7 \%$ and $17.7 \%(P=0.007)$; smokers comprised $42.8 \%$ and $34.9 \%(P=0.009)$; and second-hand smokers accounted for $46.1 \%$ and $21.2 \%(P<0.001)$, respectively. Participants in the case group reported longer sleeping and indoor hours and were more likely to live in apartments or other multi-family houses, with a lower green ratio (all $\mathrm{P}<0.001$ ), although with similar building ages, than participants in the control group.

\section{Residential radon and cigarette smoking on lung cancer}


In conditional logistic regression adjusted for second-hand smoking, sleeping and indoor hours, housing type and floor, house cracks, and green ratio, the ORs ( $95 \% \mathrm{Cls})$ for high radon and cigarette smoking were 1.56 (1.03-2.37) and 2.53 (1.60-3.99), respectively (Table 2). When stratified by combinations of radon exposure and smoking status (low-radon non-smokers [reference], high-radon smokers, low-radon smokers, and high-radon smokers), the difference in ORs for lung cancer by radon exposure was much greater in smokers than in non-smokers. That is, with low-radon non-smokers as the reference group, the adjusted ORs (95\% Cls) for lung cancer were 1.40 (0.81-2.43), $2.42(1.49-3.92)$, and 4.27 (2.14-8.52) in high-radon non-smokers, low-radon smokers, and high-radon smokers, respectively. Similar findings were observed when we used conventional, instead of conditional, logistic regression (Table 2).

Furthermore, we repeated the analysis with tobacco smoke-exposure reclassified into smoke-free group (neither smoking nor being exposed to second-hand smoke) and smoke-exposed group (active smoking and/or being exposed to second-hand smoke). Compared with the low-radon smoke-free group, the adjusted ORs for lung cancer in high-radon smoke-free, low-radon smoke-exposed, high-radon smokeexposed groups were 1.01 (0.49-2.07), 2.39 (1.48-3.87), and 4.93 (2.57-9.45) from a conditional logistic model and 1.04 (0.51-2.13), 2.41 (1.49-3.89), and 4.65 (2.44-8.88) from a conventional logistic model, respectively (Table 3 ).

Finally, we checked the robustness of our data using a lower radon cut-off value of $74 \mathrm{~Bq} / \mathrm{m}^{3}$ [19]. The adjusted ORs were 1.55 (1.02-2.34), 2.39 (1.45-3.95), and 4.16 (2.29-7.57) in high-radon non-smokers, low-radon smokers, and high-radon smokers, respectively (Table S1), and were comparable with ORs from the main analyses.

\section{Discussion}

In this matched case-control study, we discovered significant associations for lung cancer with residential radon exposure, with cigarette smoking, and with combinations of the two. Residential radon exposure and cigarette smoking were synergistically associated with a greater odds for lung cancer. Although multiplicative interaction did not reach statistical significance, the difference in ORs for lung cancer according to radon exposure was much greater in current smokers than in non-smokers. Such trend was more pronounced when environmental smoking was taken into account. In this regard, for both smokingand radon-related lung cancer risk, the most important risk reduction strategy would be smoking cessation and avoidance of environmental tobacco smoke. Conversely, among active or secondhand smokers, residential radon assessment and control should constitute a significant portion of lung cancer preventive measures, in addition to efforts supporting cessation and avoidance.

The carcinogenicity of radon and cigarette smoke may involve various mechanisms, including generation of DNA-reactive products, chromosomal instability and aberrations, and mutations of tumor-suppressor genes [20]. However, the current literature is, as of yet, inconsistent on mutation "hotspots" or unique cytogenetic markers associated with radon-related carcinogenicity or its interactions with tobacco smoke [21]. Some in vitro studies have suggested a synergistic increase of chromosomal aberrations and 
possibly a higher susceptibility to radon exposure in lymphocytes of smokers [22,23]. It has also been proposed that radon progeny may attach to tobacco smoke aerosols and increase potential doses to target organs $[24,25]$. Further molecular and cytogenetic studies are needed to elucidate the mechanism underlying the observed synergism between low-dose radon and smoking in association with lung cancer.

Epidemiologic evidence of interactions between radon exposure and cigarette smoking and their effects on lung cancer has been described in a number of studies $[9,26,27]$. However, many of these studies included persons exposed to a high doses of radon, such as those face by uranium miners [28-30]. Considering the non-linear dose-response relationship between radon and lung cancer, the modifying effect of low-dose radon on the smoking-lung cancer relationship may not be extrapolated from uranium miner results. In this study, we evaluated the interaction between residential radon and cigarette smoking, and our findings hold notable implications in lung cancer risk assessment and preventive measures. Furthermore, this is the first study in Korea to describe interactions between residential radon and cigarette smoking in association with lung cancer.

Our study has several limitations. First, the case-control design precludes causal inference between the exposure variables and lung cancer. Second, although we incorporated a matched case-control design and further adjustments for other imbalances, residual and unmeasured confounding may exist. Third, the number of female smokers in our study was too small for sex-specific analyses to be possible. Fourth, recall bias in smoking history is also possible. Finally, histopathologic subtypes of NSCLC were not differentiated in our study. Notwithstanding, this study also has some notable strengths. Foremost, we used individual-level residential radon measurements rather than ecologic data. Moreover, the cases and controls were gathered from multiple centers and cohorts of different geographic locations with varying regional radon levels. Therefore, our findings may provide some generalizability on radon exposure patterns and their associations with lung cancer in Korea.

\section{Conclusion}

In conclusion, we found both residential radon and cigarette smoking to be associated with increased odds for lung cancer, and the difference in ORs according to radon exposure was much greater in smokers than in non-smokers. Therefore, preventive strategies targeting radon-related lung cancer should emphasize, in addition to radon-reducing repairs and ventilation, both smoking cessation and withdrawing from second-hand smoking.

\section{Abbreviations}

Cl: confidence intervalOR: Odds ratio

NSCLS: Non small cell lung cancer

K-iREES: The Korea-Integrated Radon Exposure Epidemiology Statistics 
CMERC: Cardiovascular and Metabolic Diseases Etiology Research Center

KoGES: Korean Genome and Epidemiology Study

\section{Declarations}

\section{Acknowledgments}

Not applicable

\section{Availability of data and materials}

The datasets analyzed during the current study is available from the corresponding author on reasonable request.

\section{Funding}

This study was supported by the Korean Ministry of Environment as part of the "Environmental Health Action Program" (grant number: 2015001350002).

\section{Author details}

${ }^{1}$ Department of Precision Medicine \& Biostatistics, Yonsei University Wonju College of Medicine, Wonju, Korea

${ }^{2}$ Center of Biomedical Data Science, Yonsei University Wonju College of Medicine, Wonju, Korea

${ }^{3}$ Department of Preventive Medicine, Yonsei University College of Medicine, Seoul, Korea;

${ }^{4}$ Department of Internal Medicine, Yonsei University College of Medicine, Seoul, Korea;

${ }^{5}$ Cardiovascular and Metabolic Disease Etiology Research Center, Yonsei University College of Medicine, Seoul, Korea;

${ }^{6}$ Department of Pulmonary and Critical Care Medicine, Ajou University School of Medicine;

${ }^{7}$ Department of Preventive Medicine, Yonsei University Wonju College of Medicine, Wonju, Korea;

${ }^{8}$ Department of Preventive Medicine, School of Medicine, Gyeongsang National University, Jinju, Korea;

${ }^{9}$ Department of Preventive Medicine, Ajou University School of Medicine, Suwon, Korea; 
${ }^{10}$ Department of Chemical and Biological Engineering, Seokyeong University, Seoul, Korea.

†Eung Joo Park and Hokyou Lee contributed equally to this work as first authors.

\section{Corresponding author}

Dae Ryong Kang, Department of Precision Medicine \& Biostatistice, Yonsei University Wonju College of Medicine. Ilsan-ro 20, Wonju, Republic of Korea 26426 Email: dr.kang@yonsei.ac.kr

\section{Authors' contributions}

Dae Ryong Kang and Eung Joo Park designed the study. Hyeon Chang Kim, Seung soo Sheen, Sang Baek Koh, Ki Soo Park, and Nam Han Cho collected data. Eung Joo Park and Hokyou Lee performed the analyses. Hokyou Lee and Eung Joo Park drafted the article. Hyeon Chang Kim, Seung soo Sheen, Sang Baek Koh, Ki Soo Park, Nam Han Cho, MD, and Cheol-Min Lee revised the manuscript for important intellectual content. Dae Ryong Kang approved the final version of the manuscript. All authors read and approved the final manuscript.

\section{Ethics approval and consent to participate}

Subjects were informed from the study design and purpose according to the Declaration of Helsinki. Written informed consent was obtained from all subjects, and the study was approved by the institutional review board at Yonsei University Wonju College of Medicine of Korea(IRB approval number; CR315030)

\section{Consent for publication}

Not applicable

\section{Competing interests}

The authors are research and development researchers at the same Korean environment ministry, and declare that they have no conflict of interest.

\section{References}

1.Ferlay J, Soerjomataram I, Dikshit R, Eser S, Mathers C, Rebelo M, et al. Cancer incidence and mortality worldwide: sources, methods and major patterns in GLOBOCAN 2012. Int J Cancer. 2015;136:E359-86. 
2.International Early Lung Cancer Action Program I, Henschke Cl, Yankelevitz DF, Libby DM, Pasmantier MW, Smith JP, et al. Survival of patients with stage I lung cancer detected on CT screening. N Engl J Med. 2006;355:1763-71.

3.Goldstraw P, Chansky K, Crowley J, Rami-Porta R, Asamura H, Eberhardt WE, et al. The IASLC Lung Cancer Staging Project: Proposals for Revision of the TNM Stage Groupings in the Forthcoming (Eighth) Edition of the TNM Classification for Lung Cancer. J Thorac Oncol. 2016;11:39-51.

4.McKee BJ, Hashim JA, French RJ, McKee AB, Hesketh PJ, Lamb CR, et al. Experience with a CT screening program for individuals at high risk for developing lung cancer. J Am Coll Radiol. 2015;12:1927.

5.Cancer IAfRo. Monographs on the evaluation of carcinogenic risk to humans: man-made mineral fibres and radon.: Lyon, France: International Agency for Research on Cancer; 1988.

6.Alavanja MC, Brownson RC, Lubin JH, Berger E, Chang J, Boice JD, Jr. Residential radon exposure and lung cancer among nonsmoking women. J Natl Cancer Inst. 1994;86:1829-37.

7.Auvinen A, Makelainen I, Hakama M, Castren O, Pukkala E, Reisbacka H, et al. Indoor radon exposure and risk of lung cancer: a nested case-control study in Finland. J Natl Cancer Inst. 1996;88:966-72.

8.Council NR. Health effects of exposure to radon: BEIR VI: National Academies Press; 1999.

9.Bohm R, Sedlak A, Bulko M, Holy K. Use of threshold-specific energy model for the prediction of effects of smoking and radon exposure on the risk of lung cancer. Radiat Prot Dosimetry. 2014;160:100-3.

10.Tomasek L. Lung cancer risk from occupational and environmental radon and role of smoking in two Czech nested case-control studies. Int J Environ Res Public Health. 2013;10:963-79.

11.Saccomanno G, Huth GC, Auerbach O, Kuschner M. Relationship of radioactive radon daughters and cigarette smoking in the genesis of lung cancer in uranium miners. Cancer. 1988;62:1402-8.

12.Leuraud K, Billon S, Bergot D, Tirmarche M, Caer S, Quesne B, et al. Lung cancer risk associated to exposure to radon and smoking in a case-control study of French uranium miners. Health Phys. 2007;92:371-8.

13.Amabile JC, Leuraud K, Vacquier B, Caer-Lorho S, Acker A, Laurier D. Multifactorial study of the risk of lung cancer among French uranium miners: radon, smoking and silicosis. Health Phys. 2009;97:613-21.

14.Shim JS, Song BM, Lee JH, Lee SW, Park JH, Choi DP, et al. Cardiovascular and Metabolic Diseases Etiology Research Center (CMERC) cohort: study protocol and results of the first 3 years of enrollment. Epidemiol Health. 2017;39:e2017016. 
15.Kim Y, Han BG, group tK. Cohort Profile: The Korean Genome and Epidemiology Study (KoGES) Consortium. Int J Epidemiol. 2017;46:e20.

16.Yoo JI, Park JS, Kim RB, Seo AR, Park YJ, Kim MJ, et al. WHO disability assessment schedule 2.0 is related to upper and lower extremity disease-specific quality of life. Qual Life Res. 2018;27:2243-50.

17.Park JH, Lee CM, Lee HY, Kang DR. Estimation of Seasonal Correction Factors for Indoor Radon Concentrations in Korea. Int J Environ Res Public Health. 2018;15:2251.

18.Angell WJ, Zeeb H, Shannon F. WHO handbook on indoor radon: a public health perspective. 2009.

19.Kim SH, Koh SB, Lee CM, Kim C, Kang DR. Indoor Radon and Lung Cancer: Estimation of Attributable Risk, Disease Burden, and Effects of Mitigation. Yonsei Med J. 2018;59:1123-30.

20.Alavanja MC. Biologic damage resulting from exposure to tobacco smoke and from radon: implication for preventive interventions. Oncogene. 2002;21:7365-75.

21.Robertson A, Allen J, Laney R, Curnow A. The cellular and molecular carcinogenic effects of radon exposure: a review. Int J Mol Sci. 2013;14:14024-63.

22.Mohanku MN, Meenakshi C. Radon-induced Chromosome Damage in Blood Lymphocytes of Smokers. Research Journal of Environmental Toxicology. 2012;6:51-8.

23.Meenakshi C, Mohankumar MN. Synergistic effect of radon in blood cells of smokers - an in vitro study. Mutat Res. 2013;757:79-82.

24.Morawska L, Phillips CR. Attachment of Radon Progeny to Cigarette-Smoke Aerosol. Aerosol Science and Technology. 1992;17:149-58.

25.Biermann AH, Sawyer SR. Attachment of radon progeny to cigarette-smoke aerosols. Lawrence Livermore National Laboratory; 1995.

26.Kreuzer M, Walsh L, Schnelzer M, Tschense A, Grosche B. Radon and risk of extrapulmonary cancers: results of the German uranium miners' cohort study, 1960-2003. Br J Cancer. 2008;99:1946-53.

27.Denman AR, Rogers S, Ali A, Sinclair J, Phillips PS, Crockett RG, et al. Small area mapping of domestic radon, smoking prevalence and lung cancer incidence-A case study in Northamptonshire, UK. J Environ Radioact. 2015;150:159-69.

28.Hornung RW, Meinhardt TJ. Quantitative risk assessment of lung cancer in U.S. uranium miners. Health Phys. 1987;52:417-30.

29. Heidenreich WF, Tomasek L, Rogel A, Laurier D, Tirmarche M. Studies of radon-exposed miner cohorts using a biologically based model: comparison of current Czech and French data with historic data from China and Colorado. Radiat Environ Biophys. 2004;43:247-56. 
30.Tomasek L, Darby SC, Swerdlow AJ, Placek V, Kunz E. Radon exposure and cancers other than lung cancer among uranium miners in West Bohemia. Lancet. 1993;341:919-23.

\section{Tables}

Table 1. Characteristics of the study participants

\begin{tabular}{lccc}
\hline Variables & Case $(\mathrm{N}=519)$ & Control (N=519) & $p$ value \\
\hline Age, years & $64[57-72]$ & $64[59-72]$ & 0.116 \\
Sex, n (\%) & & & N/A \\
Male & $253(48.75)$ & $253(48.75)$ & \\
Female & $266(51.25)$ & $266(51.25)$ & \\
Residential radon*, Bq/m ${ }^{3}$ & $65.46 \pm 46.71$ & $73.75 \pm 60.21$ & 0.013 \\
High-radon dwellingt, $\mathrm{n}(\%)$ & $71(13.68)$ & $92(17.73)$ & 0.007 \\
Cigarette smoking, $\mathrm{n}(\%)$ & $222(42.77)$ & $181(34.87)$ & 0.009 \\
Second-hand smoking, $\mathrm{n}(\%)$ & $239(46.05)$ & $110(21.19)$ & $<0.001$ \\
Sleeping hours & $7.20 \pm 1.83$ & $6.76 \pm 1.44$ & $<0.001$ \\
Indoor hours & $15.88 \pm 4.39$ & $14.17 \pm 3.69$ & $<0.001$ \\
Housing type, n (\%) & & & $<0.001$ \\
Single-family house & $178(34.30)$ & $373(71.87)$ & \\
Apartment & $180(34.68)$ & $68(13.10)$ & \\
Other multi-family dwelling & $161(31.02)$ & $78(15.03)$ & \\
Floor of residence & $4.76 \pm 5.09$ & $2.63 \pm 3.69$ & $<0.001$ \\
Presence of house crack, n (\%) & $120(23.12)$ & $145(27.94)$ & 0.075 \\
Construction year & $1996[1990-2003] 1997[1987-2005]$ & 0.638 \\
Green ratio & $48.09 \pm 21.09$ & $56.89 \pm 18.54$ & $<0.001$ \\
\hline
\end{tabular}

*Corrected for seasonal variations.

†Residential radon $\geq 100 \mathrm{~Bq} / \mathrm{m}^{3}$.

Table 2. Associations of residential radon exposure and cigarette smoking with lung cancer 
Conditional logistic regression Conventional logistic regression

\begin{tabular}{|c|c|c|c|c|c|c|}
\hline Variables & \multicolumn{2}{|c|}{ Case, nControl, $\mathrm{n}$} & OR $(95 \% \mathrm{CI}) *$ & $p$-value & OR $(95 \% \mathrm{CI}) \dagger$ & $p$-value \\
\hline \multicolumn{7}{|l|}{ Residential radon } \\
\hline Low $\left(<100 \mathrm{~Bq} / \mathrm{m}^{3}\right)$ & 448 & 427 & 1.00 (reference) & & 1.00 (reference) & \\
\hline High $\left(\geq 100 \mathrm{~Bq} / \mathrm{m}^{3}\right)$ & 71 & 92 & $1.56(1.03-2.37)$ & 0.037 & $1.52(1.00-2.31)$ & 0.048 \\
\hline \multicolumn{7}{|l|}{ Cigarette smoking } \\
\hline Non-smokers & 297 & 338 & 1.00 (reference) & & 1.00 (reference) & \\
\hline Smokers & 222 & 181 & $2.53(1.60-3.99)$ & $<0.001$ & $2.50(1.59-3.94)$ & $<0.001$ \\
\hline \multicolumn{7}{|l|}{ Radon and smoking } \\
\hline Low-radon non-smokers & 262 & 282 & 1.00 (reference) & & 1.00 (reference) & \\
\hline High-radon non-smokers & 35 & 56 & $1.40(0.81-2.43)$ & 0.231 & $1.40(0.81-2.44)$ & 0.230 \\
\hline Low-radon smokers & 186 & 145 & $2.42(1.49-3.92)$ & $<0.001$ & $2.42(1.50-3.91)$ & $<0.001$ \\
\hline High-radon smokers & 36 & 36 & $4.27(2.14-8.52)$ & $<0.001$ & $4.02(2.03-7.97)$ & $<0.001$ \\
\hline
\end{tabular}

*Conditional logistic regression was adjusted for second-hand smoking, sleeping hours, indoor hours, housing type, floor, presence of house cracks, and green ratio. CI, confidence interval; OR, odds ratio.

†Conventional logistic regression was further adjusted for age and sex.

Table 3. Associations of residential radon and tobacco smoke exposure with lung cancer

\begin{tabular}{|c|c|c|c|c|c|c|}
\hline \multirow{2}{*}{ Variables } & \multirow{2}{*}{$\begin{array}{c}\text { Case, } \\
\mathrm{n}\end{array}$} & \multirow{2}{*}{$\begin{array}{c}\text { Control, } \\
\mathrm{n}\end{array}$} & \multicolumn{2}{|c|}{$\begin{array}{l}\text { Conditional logistic } \\
\text { regression }\end{array}$} & \multicolumn{2}{|c|}{$\begin{array}{c}\text { Conventional logistic } \\
\text { regression }\end{array}$} \\
\hline & & & OR $(95 \% \mathrm{CI})^{*}$ & $p$-value & OR $(95 \% \mathrm{CI}) \dagger$ & $p$-value \\
\hline \multicolumn{7}{|l|}{ Residential radon } \\
\hline Low $\left(<100 \mathrm{~Bq} / \mathrm{m}^{3}\right)$ & 448 & 427 & 1.00 (reference) & & 1.00 (reference) & \\
\hline High $\left(\geq 100 \mathrm{~Bq} / \mathrm{m}^{3}\right)$ & 71 & 92 & $1.56(1.03-2.37)$ & 0.037 & $1.52(1.00-2.31)$ & 0.048 \\
\hline \multicolumn{7}{|l|}{ Smoke exposure } \\
\hline Smoke-free & 122 & 254 & 1.00 (reference) & & 1.00 (reference) & \\
\hline Smoke-exposed & 397 & 265 & $2.67(1.69-4.21)$ & $<0.001$ & $2.64(1.68-4.17)$ & $<0.001$ \\
\hline \multicolumn{7}{|l|}{ Radon and smoke exposure } \\
\hline Low-radon smoke-free & 109 & 204 & 1.00 (reference) & & 1.00 (reference) & \\
\hline High-radon smoke-free & 13 & 50 & $1.01(0.49-2.07)$ & 0.956 & $1.04(0.51-2.13)$ & 0.919 \\
\hline Low-radon smoke-exposed & 339 & 223 & $2.39(1.48-3.87)$ & $<0.001$ & $2.41(1.49-3.89)$ & $<0.001$ \\
\hline $\begin{array}{l}\text { High-radon smoke- } \\
\text { exposed }\end{array}$ & 58 & 42 & $4.93(2.57-9.45)$ & $<0.001$ & $4.65(2.44-8.88)$ & $<0.001$ \\
\hline
\end{tabular}


*Adjusted for second-hand smoking, sleeping hours, indoor hours, housing type, floor, presence of house cracks, and green ratio. CI, confidence interval; OR, odds ratio.

†Conventional logistic regression was further adjusted for age and sex.

\section{Figures}

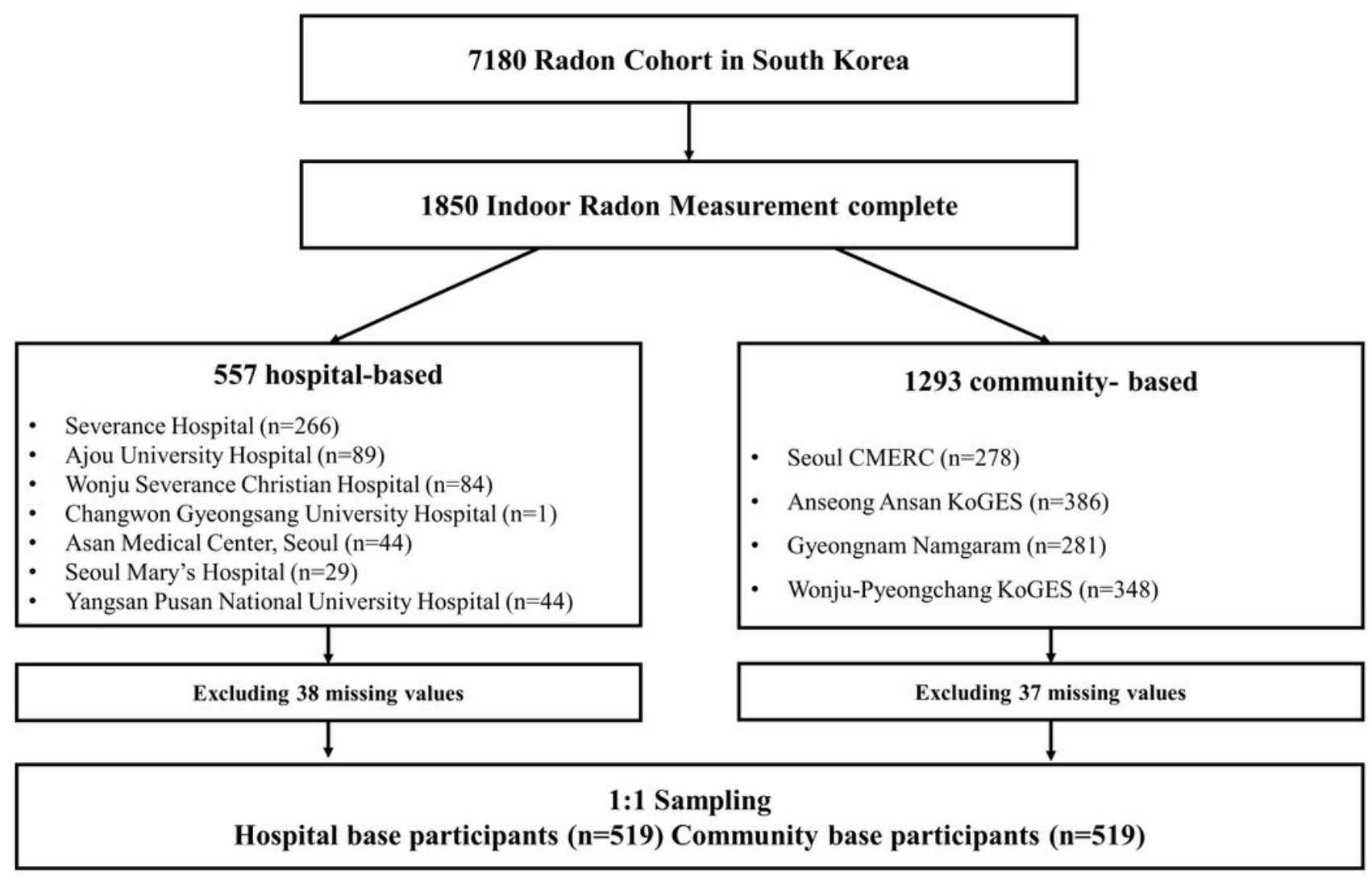

\section{Figure 1}

Flowchart of the study participants. 


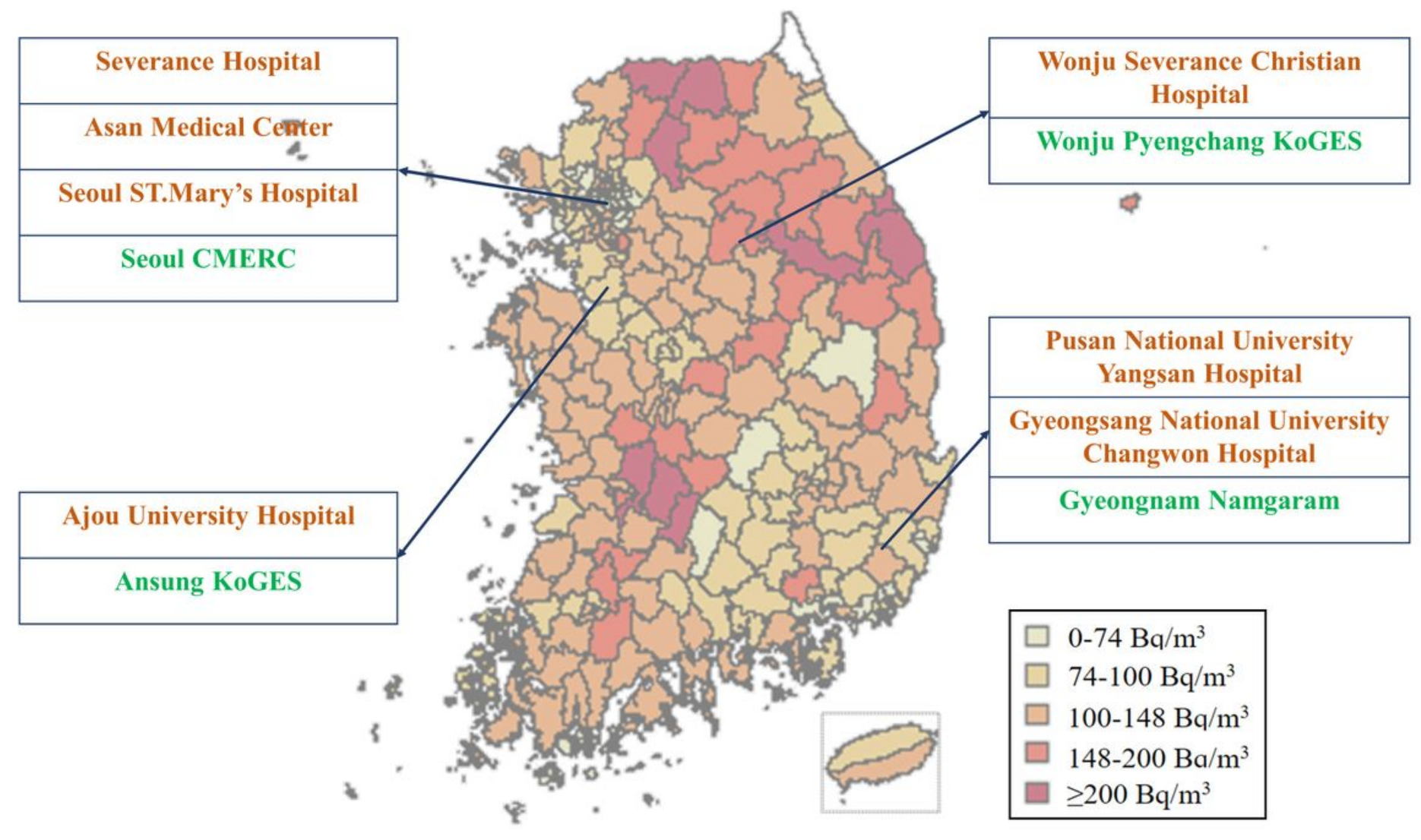

Figure 2

Map of the study area and research sites. Regional indoor radon levels were obtained from the National Institute of Environmental Research (2011-2016). Fill colors correspond to radon levels in five categories. Stars designate the locations of study sites.

\section{Supplementary Files}

This is a list of supplementary files associated with this preprint. Click to download.

- SupplementaryTable.docx 